\title{
Between Hope and Risks; Insight on Delayed Sternal Closure Technique Outcomes in Adult Patients underwent Cardiac Operations
}

\author{
Nezar El nahal* (MD), Mohamed Alanwar* (MD) \\ Cardiothoracic surgery department, Zagazig University.
}

Corresponding author:

name Mohamed Alanwar Email

anwar7666@yahoo.com

Tel.:01226673568

\begin{abstract}
Background: the delay of sternal closure after cardiac operations may offer the chance for survival in critical conditions; mainly sever hemodynamic instability and uncontrollable bleeding. Many concerns about hope of survival and possible risks especially mediastinitis or wound infection still represent dilemma for surgeons in such situations. The aim of our study is to evaluate the outcomes of delayed sternal closure technique after cardiac operations.Methods:this prospective study included 28 adult patients. Differentpreoperative, operative patient's data were collected and postoperative outcomes were recorded.Results: survival rate was $61 \%$ of patients; average time till sternal closure was $1.0 \pm 2.6$ days. Main causes of death were multi-organ failure $(n=4)$, low cardiac output $(n=4)$, sepsis $(n=3)$.Superficial sternotomy wound infection occurred in 3patients $(10.7 \%)$ while only one patient developed deep sternotomy wound infection.Conclusions : delayed sternal closure is a beneficial technique that may carry the hope of survival for highly critical patients, risk of mediastinitis or wound infection were low and should not make the surgeon hesitate to offer the patient this valuable chance for survival when needed.
\end{abstract}

Keywords: $:$ sternal,mediastinitis,hemodynamics, bleeding

\section{INTRODUCTION}

$\mathrm{C}$ ardiac surgeons today face more and more challenging situations including patients with more complex pathology that required prolonged operations, more patients with advanced ventricular dysfunction and widespread use of anticoagulants or potent antiplatelets $^{[1]}$. Due to these increasing risk factors some patients may developsever hemodynamic instability orsignificant bleeding after discontinuation of cardiopulmonary bypass, in such critical situations delayed sternal closure technique (DSC) may represent the gate for survival of thepatient ${ }^{[2]}$ Other indications of DSC include cardiac tamponade on closure, serious arrhythmias,or when either ventricular assist devices or transthoracic intraaortic balloon pumps (IABPs) are required ${ }^{[3]}$.
Potential disadvantages include risk of wound infection, loss of thoracic cage stability, possibility of cardiac injury and difficult nursing care ${ }^{[4]}$.

Most of the reports in the literature involve either small groups of patients or are case reports and correlation between risk factors and outcomes in patient managed by DSC still unclear ${ }^{[5]}$.We conduct this study to assess the outcomes of the technique in our patients specially survival, risks and complications.

\section{PATIENTS AND METHODS}

This prospective study include 28consecutive adult patients managed by delayed sternal closure technique aftercardiac operations, they were operatedat department of cardiothoracic surgery-Zagazig Universityin the period between September 2014 and December 2017. 
Inclusion criteria: adult patients who underwent coronary artery bypass grafting surgery, valve surgery or combined operation. Elective, urgent, emergent and redo cases were all included.

All preoperative data were collected include age,sex, NYHA functional class,risk factors (e.g. smoking,DM, renal function, COPD,), echocardiography data and cardiac catheter finding.

All our patients received standard cardiac general anesthesia,intravenous prophylactic $3^{\text {rd }}$ generation cephalosporinadministered before skin incision. Standard median sternotomy and cardiopulmonary bypass with mild hypothermia were used in all patients. Myocardial protection achieved with tepid antegrade blood cardioplegia, systemic temperature allowed drifting passively during $\mathrm{CPB}$ and rewarming carried out before discontinuation of CPB. After completion of the planned operation weaning and discontinuation of CPB carried out,according to situation inotropic support or IABP support applied accordingly.

At that stage or during trail of closing the sternum, indications for keeping the sternum opened became clarified; main indications included hemodynamic instability or uncontrollable bleeding. Manifestations of hemodynamic instability includes hypotension ,low cardiac output (LCOP) even with optimization of preload ,afterload , maximal inotropic support and IABP support or serious arrhythmias.

This instability occurred in some patientsbefore trial of sternal closure. In other patients significant cardiac compression effect occurred during attempts to close the sternum even when done gradually or over a time span of 15 to 30 minutes, or after trial of chest closure manifested by significant drop of blood pressure, elevation of central venous and pulmonary pressures.In group of the patients, both hemodynamic instability and uncontrollable bleeding were associated with each other.

Technique of open chest:
Sternum kept opened and whenever possible the skin only closed with continuous subcuticular suture or simple interrupted heavy silk stitches and covered with sterile dressing, a sterile gauzes or laparotomy pad kept underneath the sternal halves to protect anterior cardiac and mediastinal structures. But in cases of sever hemodynamic instability due to severe edema, dilatation of the cardiac chamber(s) or compression by paracardiac structures that could not allow skin closure ;a sternal retractor was left open in place to keep the sternum and adjacent structures away from the heart so giving more room to cardiac chamber to be filled properly without compression. The wound were completely and carefully covered with thin, transparent sheets of OPSITE ensuring complete sealing and isolation of wound from environment .On the other hand, in case of intractable bleeding, the pericardial space and mediastinumcould be packed initially with sterile gauzes or laparotomy pads, these packs were changed frequently as needed when it became soaked and finally it was removed later when bleeding subsided. The patient was kept mechanically ventilated after beingsedated during this whole period. Vancomycin added to antibiotic regimen till closure and dose adjusted according to body weight and renal function. Timing of delayed sternal closure(DSC )was determined by many factorsincluding improvement and stabilization of hemodynamics, return of the central venous pressure toward the acceptable levels, ability to taper off inotropic drugs and pharmacological support to acceptable level, resolution of myocardial edema with improvement in contractility observed during dressing , cessation of bleeding, correction of coagulation disorder ,control of arrhythmias, stable hemodynamic response to removal of sternal retractor and approximation of the sternum as a test before final decision to close the sternotomy wound.

In most of the cases we close the chest in operation room under strict aseptic condition to avoid the potential danger of serious infection. Repeated irrigation and cleaning with diluted 
povidone-iodine solution and warm isotonic saline $0.9 \%$ were performed, debridement of any devitalized tissue;finally the sternum and other layers of sternotomy incision were closed anatomically.Patients were followed in ICU and after transfer to ward till discharge.

Hospital mortality was defined as death for any reason occurring during the same hospitalization period. Sternal, neurological, renal and respiratory morbidity were recorded. Sternal complications such as superficial wound infection (SWI), mediastinits\& deep sternal wound infection (DSWI), and sternal dehiscence necessitating re-fixation were recorded.

\section{Statistical Analysis}

Data were collected and presented to (IBM SPSS) version 20. Qualitative data were obtained as number and percentages and compared by Chi-square test while quantitative data were obtained as mean, ranges and standard deviations and then compared between the two studied groups by using Independent $t$ test. The p-value was considered non significant at the level of higher than 0.05 (NS), significant at the level of less than 0.05 (S) and highly significant at the level of less than 0.01 (HS).

\section{RESULTS}

Preoperative data: Mean age of patients was $48.3 \pm 10.7$ years ,64 \% of them was male (18 patients ) and $36 \%$ were female (10 patients) . diabetes mellitus present in $36 \%$ while hypertension in $50 \%$, smoking history was positive in $46 \%$ of patients. NYHA class III and IV documented in 19 patients (68\% of patients ). Elective surgery planned in 17 patients $(60 \%)$ while urgent operations carried out in 7 patients $(25 \%)$ and emergency operations in 4 patients $(15 \%)$, redo operations represented $32 \%(n=9)$ of included patients. Types of operations included valve surgery in 14 patients $(50 \%)$, CABG in 12 patients $(43 \%)$, and combined operations in 2 patients $(7 \%)$. preoperative echocardiography showed mean EF\% was $39 \pm 15 \%$. Preoperative inotropic support required in 3 of patients due to low cardiac output .

Operative data:Average cardiopulmonary bypass time was $128 \pm 41$ minutes, and the average cross clamping time was $101 \pm 36$ minutes. Significant coagulopathy was evident in many patients who had prolonged bypass time, also cardiac and mediastinal edema noted in some patients with high central venous and pulmonary artery pressures. All patients received maximal inotropic support and some had IABP inserted intraoperatively. Attempts to close the sternum -even when done gradually or over a time span of 10 to 30 minutes-resulted in significant cardiac compression effect leading tosever drop of blood pressure and more elevation of central venous pressure. Some patients showed sever bradycardia, serious arrhythmia and cardiac distention.

Indications of DSC the indications of DSCinclude hemodynamic instability or low cardiac output (LCOP) in 18 patients $(64.2 \%)$, uncontrollable bleeding in 7 patients $(24.9 \%)$ and both hemodynamic instability and bleeding were associated with each other in 3 patients (10.7\%).This LCOP/ instability occurred in 8 Patients before trial of closure and in 9 patients during, or after trial of sternotomy closure. Serious persistent ventricular arrhythmia was the indication in one of our CABG patients.

Table (1) indications for DSC

\begin{tabular}{|l|l|l|}
\hline Indication for DSC & Number of patients & $\%$ of total \\
\hline Hemodynamic instability (LCOP) & $18 / 24$ & $64.2 \%$ \\
\hline Uncontrollable Bleeding & $7 / 24$ & $24.9 \%$ \\
\hline Both & $3 / 24$ & $10.7 \%$ \\
\hline
\end{tabular}


Incidence of DSC was $1.6 \%$ of total number of adult patients in our study.

Technique: In most of our cases (89\%) sternum kept open and skin could be closed, while in rest of patients skin and sternum kept open and sternotomy covered with adhesive sheets of OPSITE Film which is a transparent, adhesive polyurethane film . The average frequency of mediastinal dressing was 3 times before closure of the sternum.
Sternotomy closure: was performed at 1.0 \pm 2.6 days after primary operation. The average ICU stay was $4.9 \pm 7.5$ days and the average hospitalization period for the survived patients was $12 \pm 13.4$ days.

Mortality:our hospital mortality was 39\% (11 out of 28 patients). Cause of death included multi-organ failure $(n=4)$, low cardiac output $(n=4)$, sepsis $(n=3)$.Five patients died before closure of chest while other 6 patients died after closure of chest.

Table (2) mortality and causes of death

\begin{tabular}{|lll|}
\hline Survived patients & No. of patients & $\%$ of total \\
\hline 30 days Mortality & 17 & $61 \%$ \\
\hline Cause of Death & 11 & $39 \%$ \\
$\quad$ Multi-organ Failure & & \\
$\quad$ LCOP & 4 & $14 \%$ \\
$\quad$ Sepsis & 4 & $14 \%$ \\
& 3 & $10.7 \%$ \\
\hline
\end{tabular}

Complications : superficial sternotomy wound infection occurred in 3 patients $(10.7 \%)$ responded well to dressing and antibiotic therapy, only one patient developed deep sternotomy wound infection requiring debridement, irrigation, and drainage and it was directly related to sepsis and death of this patient. Renal failure occurred in 6 patients (21.4\%) mostly related to low cardiac output, sepsis, and nephrotoxic drug effect. Four patients developed pneumonia. Cerebral stroke occurred in 2 patients one of them had heavily calcified aorta, sepsis occurred in 3 patients. Two patients developed upper gastro-intestinal bleeding, both of them medically treated.

\section{DISCUSSION}

Concept of cardiac compression at time of sternal closure was established since 1975 based on Riahi and colleagues work who explained the cardio-mediastinal disproportion tamponadeeffect ${ }^{[6]}$. This effect is exaggerated in setting of edematous, noncompliant and stunned heart ${ }^{[7]}$ After the sternum re-opening there was a reported $59 \%$ increase in cardiac index and a $18 \%$ rise in systemic blood pressure, without significant change in cardiac filling pressures ${ }^{[8,9]}$.

Patients with uncontrollable bleeding or coagulopathy may further benefit because of ready access to the mediastinum for clot evacuation, moreover direct electrical cardioversion and internal cardiac massage can be performed easily and rapidly ${ }^{[10]}$.

Incidence of DSChad been increased in the modern surgical era as it became increasingly adopted by many centers and the patients' profiles became more complex. In the present study $1.6 \%$ of our patients had DSC in our center. Initial reports were similar to our results , it estimated the incidence to be about $1.7 \%$ of total number of operated adult patients ${ }^{[6]}$, while more recent reports showed 5\% and $4.2 \%$ incidences of DSC that explained higher proportion of high risk patients ${ }^{[10]}$. This management strategy has been used more frequently (9\% to 62\%) in pediatric cardiac patients ${ }^{[7]}$.

Main Indications for DSC in our study wereuncontrollable bleeding of different etiologies or significant hemodynamic instability at time of closure which were clearly 
agreed by many reports ${ }^{[1]}$. This technique gives the depressed cardiac function chance to recover and bleeding to be better controlled whether by transfusion and correction of medical factors, mediastinal packing, and easy removal of clots by surgeon preventing more coagulopathy by clotting factors consumption $^{[10]}$.Misawa suggested that sternal closure should be delayed when the mean left atrial or central venous pressure increase persisted at $2 \mathrm{mmHg}$ or more above the initial value at the tentative sternal closure as both factors were defined as risk factors based on hisprospective study that included 201 patients, after application of this method no more patient required sternal reopening because of hemodynamic deterioration in his center ${ }^{[11]}$

Anderson and associates defined poor functional class and advanced cardiac disease requiring a lengthy operation as preoperative risk factors for postoperative hemodynamic instability and hence the need for DSC, however it did not stratify patients in it's study into groups of varying possibility for mortality, they found no preoperative risk for death during admissioninhospital, and the only predictor of poor outcome intraoperative was the requirement for VAD insertion ${ }^{[12]}$. Another study proposed a link between the type of operation and the need for DSC based on their results that patients who required DSC had a higher incidence of emergency or urgent operations $21.8 \%$ and reoperative surgery (43\%) as well as a moderately depressed EF\% $46.2 \pm 19.6 \%{ }^{[10]}$. Excessive intraoperative blood loss, excessive blood transfusion and undue increases in heart size are often associated with a prolonged perfusion time and poor myocardial preservation resulting in severe ventricular dysfunction and arrhythmias that may finally require DSC ${ }^{[13]}$, these findings were generally correlated with our observations in the present study.

Hospital mortalityin our studywas 39\% (11 out of 28 patients). Causes of death included multi-organ failure $(n=4)$, low cardiac output $(n=4)$ and sepsis $(n=3)$. Five patients died before sternal closure while other 6 patients died after sternal closure.Similar ratesreported by Christenson and his group who reported overall mortality rate was $31.7 \%(10)$. Yasa and associates reported mortality rate of $27 \%$, more than half of them died before closure .Causes of death were multi-organ failure $(n=4)$, low cardiac output $(n=3)$, cardiacarrest $(n=3)$, stroke $(n=1)$, and sepsis $(n=1)(2)$.Fleck and coworkers whoused VAC system in their series of DSC patients had slightly higher overall mortality rate of $45 \%$. However no sternotomy infection was reported ${ }^{[14]}$.

Wide range of mortality rates had been reported that could be explained by wide variation of preoperative and operative risk factors in addition to complexity of conditions. For example, Shalabi and associates reported less overall mortality rate of $10 \%{ }^{[9]}$. On contrary, Furnary and colleagues in a large series included VAD patients, reported an elevated overall mortality rate of $53 \%$ which may be explained by the more critical condition of those patients who needed VAD to survive ${ }^{[8]}$.

Anderson and coworker reported that high epinephrine requirement just before chest closure, duration of high dose inotropic support, sternal infection, dialysis, reoperation for mediastinal bleeding, and prolonged time delay before sternal closure were the significant postoperative risk factors associated with mortality in DSC patient ${ }^{\text {[12]. }}$

Timing of delayed closure is a very crucial decision which should be judged with great care, as early premature closure may lead to failure with unnecessary cardiac compression and recurrent cardiac dysfunction. While late timing for closure may expose the patient to serious complications specially infectious complications. In our series DSC performed $1.0 \pm 2.6$ days when the patients became hemodynamically stable and bleeding was controlled.

Geigerand associates were unable to close the sternum in most of their cases before the 4th postoperative day, when cardiac indices approached preoperative values, and when only modest amounts of inotropic agents were required ${ }^{[15]}$. Anderson and coworkers 
performed flap closure when persistent mediastinal edema prevents sternal closure in patients who are otherwise stable. Transesophageal echocardiography is useful tool during sternotomy closure to give periodic information about ventricular function and response to sternal closure. Other respects regarding timing of closure include inotrope necessities, level of dependency on IABP support, and degree of fluid mobilization. Although the decision of when to close is made individually on a case-by-case basis, patients who had been successfully closed were generally on less than $2.0 \mu \mathrm{g} /$ minute of epinephrine and in negative fluid balance ${ }^{[12,1]}$.

In another report the average time for DSC was significantly prolonged when patients developed sternal wound infection $(80 \pm 16$ hours), and mediastinitis (108 hours), compared to those patients who did not have any sternal complications (48 \pm 33 hours).With VAC application the period until sternal closure was quitelong with a mean of $8 \pm 7$ days. The decreased risk of infection and the improvement of sternal stability compared to the open sternumwas the rationale, sothe patients could be slowly weaned from fluid overload,as well as catecholamine support ${ }^{[14]}$.

Sternotomy woundinfection average rates for patients undergoing routine cardiac operations are in the range of $0.5 \%$ to $2 \%$ Logically, it is expected that group of patients undergoing DSC is particularly at higher risk for infection, because they have predisposing factors such as: prolonged CPB time, low cardiac output, excessive bleeding and the need for multiple reexplorations of the chest with repeated mediastinal exposure ${ }^{[16]}$.

It is therefore surprising to note that, in one series the incidence of wound infections, mediastinitis and sternal dehiscence after DSC was not significantly different from a control population that had primary sternal closure.They reported superficial sternal wound infections occurred in $1.6 \%$ of patients after DSC and successfully treated with antibiotics and local debridement. Only one patient in the DSC group had mediastinitis. Various degrees of sternal instability were observed in three patients, two of whom required sternal refixation ${ }^{[4]}$.Superficial sternotomy wound infection occurred in 3 of our patients, it responded well to dressing and antibiotic therapy. Mediastinitis requiring debridement, irrigation, and drainage occurred in 1 patient and was directly related to the death of the patient .

Fleck and associatesdid not encounter any signs of wound infection in their series of patients treated with DSC and VAC therapy.They suggested that VAC was helpful when used as a bridge todelayed sternal closure was in avoidance of contamination and subsequent sternotomy, in addition to its stabilizing effect on thoracic cage with subsequentpositive effects on respiratory function ${ }^{[14]}$.

\section{CONCLUSION}

Delayed sternal closure is a beneficial technique that may carry the hope of survival for highly critical patients, surgeon should always keep this technique in mind when facing sever hemodynamic instability or uncontrollable bleeding after cardiac procedure. With application strict aseptic environment and proper use of antibiotics, risk of mediastinitis or wound infection were low and should not make the surgeon hesitate to offer the patient this valuable and may be the last chance for survival when needed.

\section{REFRENCES}

1- Boeken U, Assmann A, Mehdiani A, Akhyari P, Lichtenberg A. Open chest management after cardiac operations: outcome and timing of delayed sternal closure. European J Cardio-thoracSurg 40 (2011) 1146-1150.

2-Yasa H, Lafçı B, Yılık L, Bademci M, Şahin A, Kestelli M, Yeşil K and Gürbüz A. Delayed sternal closure: an effective procedure for life-saving in open-heart surgery. Ana do luKar di yolDerg 2010; 10: 163-7.

3- McGeehin W, Sheikh F, Donahorr JS, Lehman MJ, McVaugh H. Transthoracic 
intra-aortic balloon pump support: experience in 39 patients. Ann ThoracSurg 1987;44:26-30.

4- Fleck T, Moidl R, Giovanoli P, Aszmann O, Bartunek A, Blacky A, Grabenwoger M, Wolner E. A conclusion from the first 125 patients treated with the vacuum assisted closure system for postoperative sternal wound infection. Interact CardiovascThoracSurg 2006;5:145-149.

5- Milgater E, Uretzky G, Shimon DV, Silberman S, Appelbaum A, Borman JB.

Delayed sternal closure following cardiac operations. J CardiovascSurg 1986;27:328 31.

6- Riahi M, Tomatis L, Schlosser R. Bertolozzi E, Johnston D. Cardiac compression due to closure of the median sternotomy in open heart surgery. Chest 1975;67:113-114.

7- Takayama H, Leone R, Aldea G, Fishbein D, Verrier E, Salerno C. Open-chest management after heart transplant. J Texas Heart Inst 2006; 33:306-9.

8- Furnary A, Magovern J, Simpson K, Magovern G. Prolonged open sternotomy and delayed sternal closure after cardiac operations. Ann ThoracSurg 1992:54: 2339.

9- Shalabi R, Amin M, Ayed A, Shuhiber H. Delayed sternal closure is a life saving decision. Ann ThoracCardiovascSurg 2002; 8:220-223.
10- Christenson J, Maurice J, Simonet F, Velebit V, Schmuziger M. Open chest and delayed sternal closure after cardiac surgery. Eur J CardiothoracSurg 1996;10:305-311

11- Misawa Y.What can be an indicator of delayed sternal closure after cardiac surgery? Eur J CardiothoracSurg 2002;22:493-494.

12-Anderson C, Filsoufi F, Aklog L, Farivar R, Bryne J, Adams D. Liberal use of delayed sternal closure for postcardiotomy hemodynamic instability. Ann ThoracSurg 2002;73:1484-1488.

13- Fanning W, Vasko J, Kilman J. Delayed sternal closure after cardiac surgery. Ann ThoracSurg 1987;44:169-72.

14- Fleck T,Kickinger B, Moidl R, Waldenberger F, Wolner E,

Grabenwoger M and Wisser W. Management of open chest and delayed sternal closure with the vacuum assisted closure system: preliminary experience. Interact CardioVascThoracSurg2008; ; :801-804

15- Geiger J, Tabak C, Aronstam E. Primary sternal closure and mediastinal decompression by Inlay autologus rib grafts. Ann ThoracSurg 1996;61:215-216.

16- Cotogni P, Barbero C, Rinaldi M. Deep sternal wound infection after cardiac surgery: Evidences and controversies. World J Crit Care Med 2015 November 4; 4(4): 265-273. 